\title{
Boosting Purchase Intention and Online Participation Through Passion
}

\author{
Carolina Herrando ${ }^{1, *}$, Julio Jiménez-Martínez ${ }^{2}$, María José Martín De Hoyos ${ }^{3}$ \\ ${ }^{1,2,3}$ University of Zaragoza, Spain \\ ${ }^{1}$ cherrand@unizar.es*; ${ }^{*}$ jjimenez@unizar.es; ${ }^{3}$ mjhoyos@unizar.es \\ * corresponding author
}

\begin{abstract}
This study analyzes the role of passion in engaging users and how it affects purchase intention and participation in social commerce contexts. Based on marketing research, the engagement generation process is studied through the interactions among social presence,interactivity, enjoyment, sPassion, purchase intention and spread of sWOM. The results have empirically confirmed that social interactions and information exchange derived from the process boost user participation and the intention to purchase. At the core of the process, sPassion positively affects the spreading of sWOM. The introduction of the new concept sPassion brings new challenges and opportunities to marketing research, helping to develop the concept of engagement and furthering research on WOM valence. Knowing how sPassion is formed and what factors are key to its creation enable companies to understand the necessary steps to enhance user participation in social commerce contexts.
\end{abstract}

Keywords: Passion; engagement; social commerce;

\section{Introduction}

What is passion? Everybody has, at some time,experienced passion;passion for a summer love, passion for a job, passion for a football team, and even passion for our favorite brand. From a marketing perspective, some authors relate passion with brand love[1]and with engagement[2-4]. According to a qualitative study carried out by Hollebeek [3], participants state that the feeling of engagement on the Internet was materialized as a sense of passion for the activity they were performing. Previous research has demonstrated that,if a company wants to succeed on the Internet, it should not only provide useful technology on its website, but also encourage engagement among its users $[5,6]$. Would passion bes way to create this engagement in social commerce contexts?

Engagement has been considered a key element in social commerce contexts (hereafter s-commerce). S-commerce is characterized by the combination of social interactions and information exchange[7], two key elements of engagement[8].This combination makes the individual feel part of the company[9], which generates more engagement than that achieved with traditional e-commerce sites. Some studies state that engagement is the result of a process $[4,8,10,11]$. It has been shown that the affective side is the cornerstone of the engagement process, both offline [12]andonline [11]. Affections Have Been measured through attributes like enjoyment [13,14]and passion [3].However, enjoyment by itself is a feeling that needs to be accompanied by a deeper experience to allow user engagement. Engaged users show emotional attachment, dedication and passion[15]. Therefore, we propose that, ins-commerce contexts, characterized by user interaction and socialization, passion plays a key role in the engagement generation process because relationships are the basis of that type of electronic commerce.

The aim of this research is to conceptualize passions-commerce contexts. To do so, we coin the term sPassion, referring to the passion that occurs on these websites. We will study the role of sPassion to engage users, and how it positively affects the participation of these users in the form of sWOM. We propose a model that collects the factors that measure the perceptions of the individual in online engagement[16]and the relationships among them. This model will explain to practitioners how increasing the sense of passion of potential users will be beneficial for the success of s-commerce websites. The contribution of this investigation is to lay the foundations of engagement generation based on encouraging sPassion, a positive affective feeling that might enhance the spread of positive WOM. 


\section{Theoretical Background}

\subsection{The Concept of Passion}

In the marketing literature, passion has been defined as "a strong engagement in the passionate activity" [17]. In consumer research, the use of the term can be explained because passionate consumers can love an object in the same wayasa person can fall in love with somebody [18-20].In marketing perspectives, passion has been studied to explain customers' feelings toward a brand, describing this passion as "a primarily effective, extremely positive attitude toward a specific brand that leads to emotional attachment and influences relevant behavioral factors" [19], being "the core of strong and high quality consumer-brand relationships" [21], and,in the process of customer brand engagement, what leads consumers to employ expressions such as passionate, mad for, obsessive, loving, adoring, etc., when they refer to passion for a brand [3].

When it comes to purchasing and engaging online, as well as adoring a brand, users need to be passionate about the website and its navigation. That is, if the website does not fulfill users' expectations, they may express their disappointment and leave it.The real importance of passion in marketing strategies on the Internet is the fact that passionate consumers tend to share this excitement through positive WOM and act as brand evangelists $[18,19,22,23]$. Research on passion in e-commerce contexts is scarce, with the exception of investigations focused on positive WOM as an outcome of passion. However, these studies primarily focus on brand passion, disregarding the potential of passion as the main element in the engagement generation process.

S-commerce contexts, focused on the relationships between users that encourage participation and socialization[7], are appropriate places to share passion between users through positive WOM, because passion can be contagious [24]. Thanks to experiencing positive emotions on s-commerce websites, the affective stage is closely related to eWOM[10,25], which is how users communicate and interact. Therein lies the importance of studying the perception of passion in s-commercecontexts, since the relationships established there are different from other kinds of exchanges. Consistent with brand love[1] and brand passion [22,26] investigations, passion plays a major role in the spreading of positive WOM.

We define sPassion as a positive affective feeling that s-commerce users experience as a result of enjoying, interacting and socializing among users and with the company, which leads to the individual being emotionally and commercially engaged with the s-commerce website. sPassion leads to engagement because its capacity to create an emotional bond between the user and the website converts it into the cornerstone of the engagement generation process in e-commerce contexts.

\section{Hypotheses Development}

\subsection{Social Presence and Interactivity}

The perception of interaction with another human being in online environments has been called social presence [28]. Sociability and human contact are absent in e-commerce, and that's why websites that raise perceived social presence might encourage positive attitudes attitudes towards Internet shopping [29]. This socialization or social presence can influence users' attitude towards the website, through their involvement, committed behavior, co-presence and affective or cognitive social presence [30]. According to Kumar and Benbasat [31], recommendations and reviews that can be found on s-commerce websites have both a transactional and a relational function, where social presence is increased. Smith and Gallicano [15]consider the sense of presence as a variable of online engagement, defining engagement as a state of mind characterized by passion, dedication and emotional attachment, where interactivity per se is necessary but not enough to engage users. Interactivity has been used in the study of customer engagement [32] and, through interactivity on websites, users can evolve from being passive to active and interactive consumers [33]. According to Mollen and Wilson [34], building on interaction, users begin to create their cognitive experience on a website. In an investigation about entrepreneurial passion, Cardon et al.[35]consider that interaction is necessary to experience passion. Therefore, we hypothesize that social presence and interactivity can act as antecedents of sPassion.

H1a: Social presence has a positive effect on users' sPassion.

H1b: Perceived interactivity has a positive effect on users' sPassion 


\subsection{Enjoyment}

Enjoyment is one of the feelings that must be experienced because it is necessary to experience a positive feeling that engages users [13].Vivek et al. [4], in their research about online engagement, consider entertainment and passionas affective components, and Cardon and Kirk [36] add that enjoyment is a key dimension of passion. In the case of students' engagement, Case [37] considers that,to become passionate about an activity, individuals first need to experience enjoyment, which is what generates engagement. Passion and enjoyment could be linked; however, we consider that when an activity ends, enjoyment also finishes, while passion remains. Based on the above discussion, we hypothesize that enjoyment is an antecedent of sPassion.

H2: Enjoyment has a positive effect on users's Passion

\subsection{Purchase Intention And Spreading of Positive sWOM}

It is believed that engaged users play a major role in making recommendations and referrals $[10,16]$. Therefore, for s-commerce, based on information exchange and social interactions, it is essential to encourage engagement.Social WOM or sWOM refers to users' active participation on s-commerce platforms in the form of recommendations, reviews, referrals, ratings, collaborations in forums and virtual communities, etc. In online environments, engaged users may increase the spread of positive WOM[4]. Online engagement behaviors have been directly related to collaborative behaviors such as WOM, recommendations and user-generated content [10]. Smith and Gallicano [15]affirm that becoming engaged involved making assessments about personal relativity of content for the purpose of consuming, linking and sharing the content. Recent studies have shown that positive WOM and brand evangelism are outcomes of brand passion $[18,19,22,23,26]$. Additionally, we also study the direct and indirect effect of sPassion on purchase intention and positive sWOM.

H3: User perception of sPassion has a positive effect on purchase intention.

H4: User perception of sPassion has a positive effect on positive sWOM.

H5: Purchase intention has a positive effect on positive sWOM.

The model proposes that sPassion is the cornerstone of the engagement generation process where social presence, perceived interactivity and enjoyment are antecedents, and purchase intention andsWOM are the outcomes (Figure $1)$.

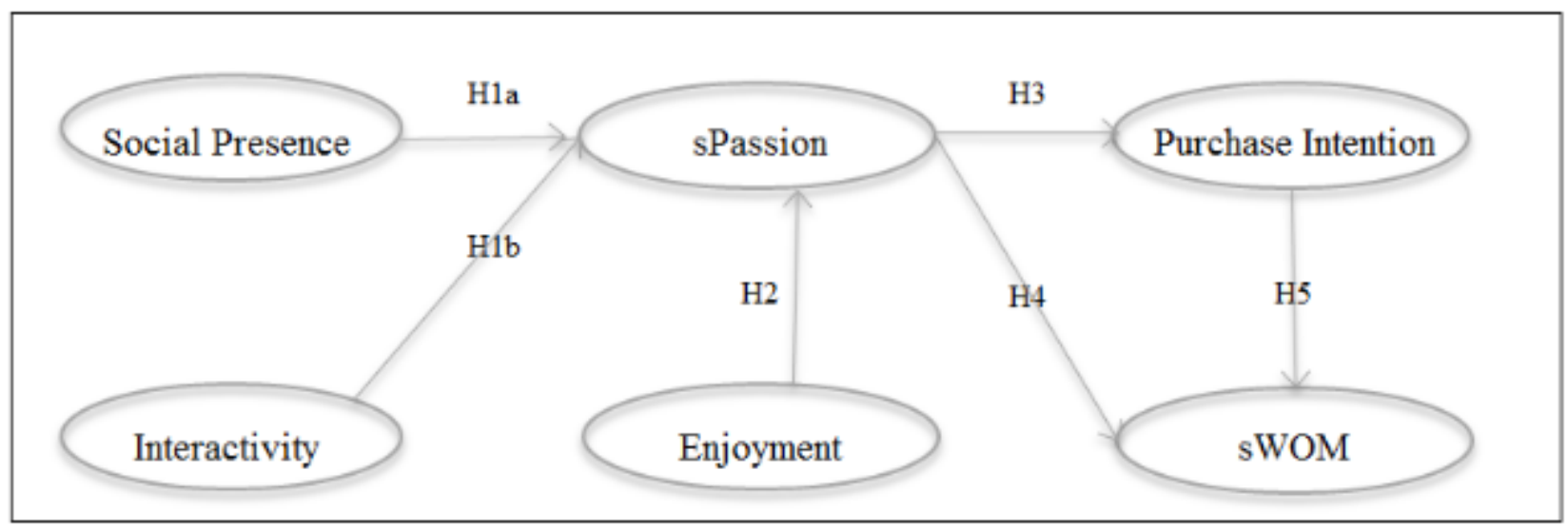

Figure. 1. Research model: engagement generation process

\section{Methodology}

\subsection{Data Collected}

The data used for this analysis were collected in Spain during the month of February 2015 through an online survey that was administered to a panel of users. The representativeness of the data was assessed considering the figures from the annual report of the Spanish National Observatory of Telecommunications and Information Society [38]. The sample consists of 473 responses, of which $59 \%$ are male and $41 \%$ female, aged between 16 and 80 . All respondents are online buyers who had recently bought on s-commerce websites such as Amazon, AliExpress, Booking, etc.

In order to assure content validity, we thoroughly reviewed the literature about the variables included in our model,adapting them to the s-commerce context. The survey was checked by several experts. Social presence is 
adapted from the scales of Gefen and Straub [39], Shen [40], and Hassanein and Head [29], and consists of 3 items. Interactivity is adapted from the scales of Song and Zinnkhan [41], McMillan and Hwang [42], and Liu [43], and is composed of three items. Enjoyment Is measured using the scales of Koufaris [44]and Kim and Han [45], with 3 items. The concept of sPassion is created from the scale of Baldus et al.[46]and consists of 6 items. The latter paper developed a scale to measure online brand community engagement but, instead of using all its factors, we have only taken those related to sPassion (brand passion and helping). Finally, sWOM is created from the scale proposed by Liang et al.[47] with 4 items, and purchase intention is adapted from the scale used by Kim and Park [58] and Hausman and Siekpe [59], and it is composed of 3 items(see Appendix). All the survey variables were measured on a 7-point Likert scale, the lowest score being 1 strongly disagree, and the highest 7 strongly agree.

\subsection{Measurement Model Validation}

To ensure the dimensionality, reliability and validity of the scales, we conducted an exploratory factor analysis and a confirmatory factor analysis using the statistical software SPSS version 22 and EQS 6. As shown in Table 1, Cronbach's alpha was higher than the recommended value of 0.70 [48], and the item-total correlation was at least $0.30[49]$.

The next step was to conduct an exploratory factor analysis to assess the degree of unidimensionality of the proposed scales using the Principal Axis Factoring method and Varimax rotation with Kaiser [50-52], where the Kaiser-Meyer-Olkin values were all greater than the threshold of 0.70 and Bartlett's sphericity tests were significant. The data also showed that the factor loadings were greater than the required minimum of 0.50 [50] and the explained variances for each of the constructs were at least $70 \%$.

Finally, a confirmatory factor analysis with the robust method was conducted. The results showed that the model fitted the data well and that all estimated coefficients are significant, so we did not have to remove any item. The factor loadings were greater than the accepted value of 0.50 and the recommended value of 0.70 . We also calculated the composite reliability index [53], which must be greater than 0.70 , and the extracted variance or AVE, which shows consistency with values higher than 0.50 [54]. We can conclude that the scales met the requirements of reliability. The results of these analyses are shown in Table 1.

Table. 1. Measurement model results

\begin{tabular}{|c|c|c|c|c|c|c|c|c|c|}
\hline & Ítem & $\begin{array}{c}\text { Cronbach's } \\
\alpha\end{array}$ & CR & AVE & $\begin{array}{c}\% \\
\text { Explained } \\
\text { variance }\end{array}$ & $\begin{array}{c}\text { Kaiser- } \\
\text { Meyer- } \\
\text { Olkin }\end{array}$ & t-value* & R-Sq & $\Lambda$ \\
\hline $\begin{array}{l}\text { Social } \\
\text { presence }\end{array}$ & $\begin{array}{l}\text { SP1 } \\
\text { SP2 } \\
\text { SP3 }\end{array}$ & 0.925 & 0.924 & 0.803 & 86.89 & 0.794 & $\begin{array}{l}22.668^{*} \\
24.953^{*} \\
25.953 *\end{array}$ & $\begin{array}{l}0.774 \\
0.810 \\
0.824\end{array}$ & $\begin{array}{l}0.880 \\
0.900 \\
0.908\end{array}$ \\
\hline Interactivity & $\begin{array}{l}\text { INT1 } \\
\text { INT2 } \\
\text { INT3 }\end{array}$ & 0.829 & 0.831 & 0.621 & 74.53 & 0.713 & $\begin{array}{l}15.171^{*} \\
17.353^{*} \\
14.982^{*}\end{array}$ & $\begin{array}{l}0.581 \\
0.691 \\
0.591\end{array}$ & $\begin{array}{l}0.762 \\
0.831 \\
0.769\end{array}$ \\
\hline Enjoyment & $\begin{array}{l}\text { ENJ1 } \\
\text { ENJ2 } \\
\text { ENJ3 }\end{array}$ & 0.877 & 0.882 & 0.715 & 80.36 & 0.717 & $\begin{array}{l}14.000^{*} \\
20.328^{*} \\
19.218^{*}\end{array}$ & $\begin{array}{l}0.585 \\
0.736 \\
0.823\end{array}$ & $\begin{array}{l}0.765 \\
0.858 \\
0.907\end{array}$ \\
\hline sPassion & $\begin{array}{l}\text { sPASS1 } \\
\text { sPASS2 } \\
\text { sPASS3 } \\
\text { sPASS4 } \\
\text { sPASS5 } \\
\text { sPASS6 }\end{array}$ & 0.924 & 0.924 & 0.670 & 72.50 & 0.874 & $\begin{array}{l}22.211^{*} \\
18.402^{*} \\
24.225^{*} \\
24.099^{*} \\
21.732^{*} \\
21.935^{*}\end{array}$ & $\begin{array}{l}0.681 \\
0.587 \\
0.707 \\
0.694 \\
0.661 \\
0.692\end{array}$ & $\begin{array}{l}0.825 \\
0.766 \\
0.841 \\
0.833 \\
0.813 \\
0.832\end{array}$ \\
\hline
\end{tabular}


Herrando et al / Vol. 3, No. 3, December 2020, pp. 136-145

\begin{tabular}{|c|c|c|c|c|c|c|c|c|c|}
\hline $\begin{array}{l}\text { Purchase } \\
\text { Intention }\end{array}$ & $\begin{array}{l}\text { PI1 } \\
\text { PI2 } \\
\text { PI3 }\end{array}$ & 0.925 & 0.926 & 0.808 & 87.00 & 0.751 & $\begin{array}{l}17.031^{*} \\
21.104^{*} \\
19.209^{*}\end{array}$ & $\begin{array}{l}0.773 \\
0.882 \\
0.769\end{array}$ & $\begin{array}{l}0.879 \\
0.939 \\
0.877\end{array}$ \\
\hline $\begin{array}{l}\text { Social } \\
\text { WOM }\end{array}$ & $\begin{array}{l}\text { sWOM1 } \\
\text { sWOM2 } \\
\text { sWOM3 } \\
\text { sWOM4 }\end{array}$ & 0.858 & 0.860 & 0.606 & 70.36 & 0.751 & $\begin{array}{l}21.196^{*} \\
18.890^{*} \\
18.984^{*} \\
16.895^{*}\end{array}$ & $\begin{array}{l}0.661 \\
0.627 \\
0.598 \\
0.540\end{array}$ & $\begin{array}{l}0.813 \\
0.792 \\
0.773 \\
0.735\end{array}$ \\
\hline \multicolumn{10}{|c|}{$\begin{array}{l}\text { Satorra-Bentler Scaled Chi-Sq }=541.518,194 \text { d.f., } p<0.01 \text {; Bentler-Bonett Normed Fit Index }(\mathrm{NFI})=0.90 \text {; Bentler- } \\
\text { Bonett Nonnormed Fit Index }(\mathrm{NNFI})=0.92 \text {; Comparative Fit Index }(\mathrm{CFI})=0.93 \text {; Bollen }(\mathrm{IFI}) \text { Fit Index }=0.93 \text {; Root } \\
\text { Mean-Sq. Error of Approximation (RMESA) }=0.06 \\
* \text { Significant coefficients at } 0.01 \text { level. }\end{array}$} \\
\hline
\end{tabular}

Scale validity was confirmed through the analysis of convergent validity and discriminant validity. Convergent validity was tested checking the significance [55] and the value of each item (as a minimum, they must exceed 0.5 points). Discriminant validity guarantees that the scales represent substantially different concepts.In our analysis, we used the average variance extracted analysis to compare, in a symmetric matrix, whether the AVE on the diagonal is larger than its corresponding squared correlation coefficients in its rows and columns, showing discriminant validity[50,54].

\section{Result}

\subsection{Structural model examination}

After carrying out the exploratory and confirmatory analyzes, the structural model was examined to test the hypotheses. The model fit indexes show acceptable values (Satorra-Bentler Scaled Chi-Sq =752,927, $197 \mathrm{df} p<0.01$; Bentler-Bonett Normed Fit Index $(\mathrm{NFI})=0.86$; Bentler-BonettNonnormed Fit Index $(\mathrm{NNFI})=0.87$; Comparative Fit Index $(\mathrm{CFI})=0.89$; Bollen $(\mathrm{IFI})$ Fit Index $=0.89$; Root Mean-Sq. Error of Approximation $(\mathrm{RMESA})=0.08 ;(\chi 2 / \mathrm{df})$ $=3.822$ ). However, we should explain that the normed chi-square (Chi-Sq / df) is above the recommended cut-off of 3 [56] because of the large size of the sample and not because of internal consistency problems, since all loading factors are statistically significant and above 0.50 [50] and the goodness of fit indexes are acceptable. None of the hypotheses had to be rejected.

The findings show that, firstly, social presence $(\beta=0.41, \mathrm{p}<0.01)$, perceived interactivity $(\beta=0.23, \mathrm{p}<0.01)$, and enjoyment $(\beta=0.50, \mathrm{p}<0.01)$ on s-commerce websites positively influence sPassion. Secondly, on the one hand, sPassion $(B=0.50, p<0.01)$ has a positive effect on purchase intention; on the other hand, sPassion $(B=0.49, p$ $<0.01)$ also has a positive influence on sWOM, that is, if the user is passionate, is more prone to spread sWOM. Finally, there is also a positive effect between purchase intention $(B=0.33, p<0.01)$ and sWOM. All in all, $51 \%$ of the sWOM variance is explained by two ways: on the one hand, through the direct effects of sPassion and purchase intention on sWOM; and, on the other hand, by the indirect effect of sPassion on sWOM through purchase intention. It should be noted that the direct effect between sPassion and sWOM $(\beta=0.49)$ is stronger than the direct effect between purchase intention and $\operatorname{sWOM}(\beta=0.33)$, and the effect is even greater if we take into account the total effect of sPassion on sWOM, which is the sum of the direct and indirect effects on sWOM $(\beta=0.65=0.50 \cdot 0.33+$ $0.49)$.

The aim of this study was to conceptualize passion in s-commerce contexts, sPassion. On the basis of the literature review and the empirical results, we define the concept of sPassion as the extent to which s-commerce users experience a positive affective feeling as a result of enjoying, interacting and socializing among users and with the company. The findings show that interactivity has a positive effect on user engagement, which supports Cardon et al. [35], and socialization entails higher levels of involvement [57]. Consistent with previous studies [1,15,22,23], the results indicate that Passion positively affects users' participation in the form of spreading sWOM. Therefore, sPassion can be considered a cornerstone that generates engagement in s-commerce. 


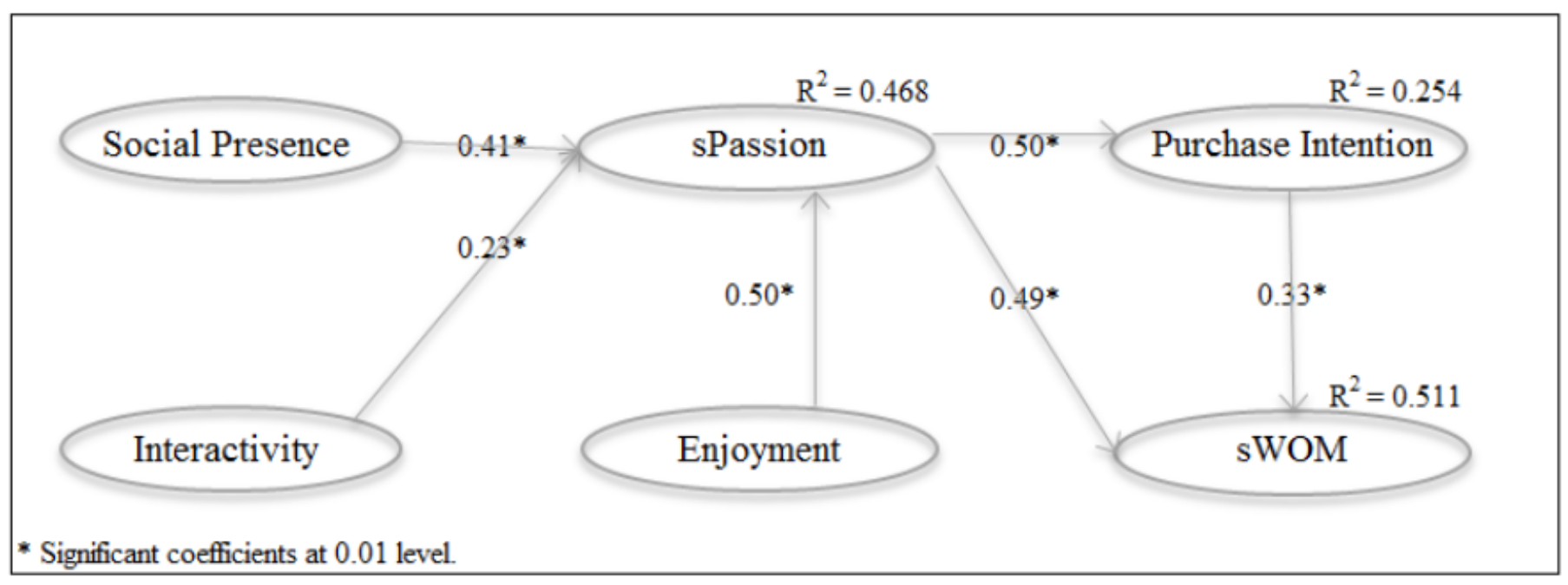

Figure. 2. Structural equation model: engagement generation process

\section{Conclusion}

\subsection{Conclusions and discussion}

The objective of this study was to analyze the concept of sPassion within the engagement generation process so as to study its role as a booster of purchase intention and user participation in s-commerce contexts, leading users to be engaged. Based on the proposal of Brodie et al. [8], the originality of our research is that we propose sPassionas the cornerstone of the engagement generation process, considering it as the positive affective feeling that individuals experience on s-commerce websites. As a result of interacting and socializing with other users and with the company, they become emotionally and commercially engaged with the s-commerce website and their purchase intention increases. The empirical findings allow us to conclude that, in order to experience the feeling of engagement, the user must first gain experience and knowledge from interaction and socialization on s-commerce websites and enjoy the experience, thus experiencing a sense of passion. As a result of this, consumers' behavior leads to an increase in spreading sWOM and purchasing intention.

The results of our study allow us to draw the following conclusions. Firstly, it has been shown that social interactions and information exchange on s-commerce websites positive influences users' emotional experience. The significance of s-commerce websites, where one can give an opinion, advise others, ask questions in a forum and share an experience, is subject to these tools available for enhancing interaction and socialization on the website. That is, the users' perception of interactivity depends heavily on interactions, but also on the communication options available on the website. The chance to interact on a website, by itself, is not what drives us to passion; it is necessary to perceive interactivity and socialization as well as experience enjoyment. The human contact experienced on a website when social presence is perceived has positive effects on users. If users imagine themselves surrounded by people instead of computers, they feel closer to an offline experience and, therefore, show affections similar to those they feel in real life. It has also been shown that enjoyment in s-commerce content boosts users' sPassion. Although, some research refers to these feelings online, passion has not been studied quantitatively to date as a variable in s-commerce contexts.

When users experience sPassion, their behavior is positively affected, supporting the idea of Brodie et al. [8] that, engagement modifies users' behavior. Once users have acquired knowledge from their experience on s-commerce websites and they feel emotionally connected to it, they will transform their behavior in accordance with the feelings they have experienced. So they will be more willing to spread sWOM because they want to share their experience and give their personal opinions. Becauses Passion is defined as a positive affective feeling, users who experience the sense of passion will report a positive experience. So, companies concerned about the valence of the WOM on their s-commerce websites -those whose marketing efforts are focused on fostering positive comments, high ratings, etc. can find, in sPassion, an efficient way of affecting users so that they share their positive experience and opinion. 
Finally, consistent with the idea that passion can be contagious [24], the engagement generation process seems to be a living process because the model involves continuous feedback, that is, the behavior of users who have been through the whole process will help other users through their comments and improve their perceptions of each step by increasing their engagement with the company. Through positive WOM, users may spread their passion and influence other users' behavior.

\subsection{Implications for business and academia}

This study opens new horizons for both marketers and researchers. These implications for business because knowing how sPassion is formed and what factors are key to its creation enable companies to understand the necessary steps to enhance users' participation in s-commerce contexts. Once users are engaged, they act autonomously as brand promoters, commenting and sharing their purchase experience with the virtual community and, given that sPassion and enjoyment are related to positive feelings, it is to be expected that these comments will have positive connotations. In this way, companies can make the most of the information and experiences shared by users because it is well-known other users consider this information more trustworthy than that coming from the company.

S-commercials are very important for generating engagement. The relationships that are established on these websites have an affective component that makes them optimal platforms to engage users. Therefore, s-commerce websites should be designed to encourage interaction between users, to share information and to boost participation since, in this type of online commerce, it is the users who create the virtual community. It has also been shown that sense of human contact and interactivity favor the integration of users on the website and, as a consequence, the possibility of feeling passion increases. But, in addition to the tools that facilitate interpersonal relationships on the web, companies should encourage enjoyment.

In order to create engagement on s-commerce websites, companies need a twofold purpose. Firstly, they should create an interactive atmosphere in which users are seen as humans, not as machines, fomenting enjoyment and passion. Secondly, although the term passion has been used as a dimension of brand love [1], in the brand passion dualistic approach [2], and to describe the concept of engagement [3,4,15], the introduction of the concept of sPassion may have theoretical implications, opening a new line of research on passion in marketing. Our study can help companies to create an affective feeling that has positive effects on users' participation and purchase intention. Furthermore, in addition to trying to help in the development of the engagement concept, we hope that this study will contribute to research on WOM valence, since sPassion is directly associated with positive sWOM.

\subsection{Limitations and future lines of research}

This study is not without limitations. Firstly, the sample of the study is focused on a single country so future research should collect data from other countries in order to carry out comparative analyzes. To a greater or lesser extent, all websites work in the international market and are visible globally, it would be interesting to conduct a cross-cultural study to examine whether there are differences in passion and in the way users become engaged. Secondly, we do not test what factors may influence enjoyment. So, as future lines of research, we propose widening the model in order to analyze what components related to s-commerce website design create or positively affect user enjoyment. Finally, the sample consists of respondents between 16 and 80 years old, in forthcoming research, we would like to introduce age as a moderator so as to study possible differences between groups.

\section{References}

[1] Batra, R., Ahuvia, A. and Bagozzi, R.P. Brand love. Journal of Marketing, 76, 2 (2012), 1-16.

[2] Vallerand, R.J., Blanchard, C., Mageau, G.A., Koestner, R., Ratelle, C., Léonard, M., Gagné, M. and Marsolais, J. Les passions de l'âme: on obsessive and harmonious passion. Journal of Personality and Social Psychology, 85, 4 (2003), 756-767.

[3] Hollebeek, L. Exploring customer brand engagement: definition and themes. Journal of Strategic Marketing 19, 7 (2011), 555-573.

[4] Vivek, S.D., Beatty, S.E. and Morgan, R.M. Customer engagement: Exploring customer relationships beyond purchase. Journal of Marketing Theory and Practice, 20, 2 (2012), 122-146.

[5] O'Brien, H.L. and Toms, E.G. What is user engagement? A conceptual framework for defining user engagement with technology. Journal of the American Society for Information Science and Technology, 59, 6 (2008), 938-955. 
[6] O'Brien, H.L. and Toms, E.G. The development and evaluation of a survey to measure user engagement. Journal of the American Society for Information Science and Technology, 61, 1 (2010), 50-69.

[7] Zhang, H., Lu, Y., Gupta, S. and Zhao, L. What motivates customers to participate in social commerce? The impact of technological environments and virtual customer experiences. Information \& Management, 51, 8 (2014), 1017-1030.

[8] Brodie, R.J., Ilic, A., Juric, B. and Hollebeek, L. Consumer engagement in a virtual brand community: An exploratory analysis. Journal of Business Research, 66, 1 (2013), 105-114.

[9] Blasco-Arcas, L., Hernandez-Ortega, B. and Jimenez-Martinez, J. The online purchase as a context for co-creating experiences. Drivers of and consequences for customer behavior. Internet Research, 24, 3 (2014), 393-412.

[10] Groeger, L., Moroko, L. and Hollebeek, L. Capuring Value from Non-Paying Consumers' Engagement Behaviors: Field Evidence and Development of a Theoretical Model. Journal of Strategic Marketing, Forthcoming 2016.

[11] Hollebeek, L.D. The customer engagement / value interface: An exploratory investigation. Australasian Marketing Journal, 21, 1 (2013), 17-24.

[12] Westbrook, R.A. Product / consumption-based affective responses and postpurchase processes. Journal of Marketing Research, 24, 3 (1987), 258-270.

[13]Kim, Y.H., Kim, D.J. and Wachter, K.A study of mobile user engagement (MoEN): Engagement motivations, perceived value, satisfaction, and continued engagement intention. Decision Support Systems, 56, (2013), 361-370.

[14] Calder, B.J., Malthouse, E.C. and Schaedel, U. An experimental study of the relationship between online engagement and advertising effectiveness. Journal of Interactive Marketing, 23, 4 (2009), 321-331.

[15] Smith, B.G. and Gallicano, T.D. Terms of engagement: Analyzing public engagement with organizations through social media. Computers in Human Behavior, 53, (2015), 82-90.

[16]Brodie, R.J., Hollebeek, L.D., Juric, B. and Ilic, A. Customer engagement: conceptual domain, fundamental propositions, and implications for research. Journal of Service Research, 14, 3 (2011), 252-271.

[17] Lavigne, G.L., Forest, J. and Crevier-Braud, L. Passion at work and burnout: A two-study test of the mediating role of flow experiences. European Journal of Work and Organizational Psychology, 21.4 (2012), 518-546.

[18] Matzler K, Pichler EA, Hemetsberger A. Who is spreading the word? The positive influence of extraversion on consumer passion and brand evangelism. Marketing Theory and Applications 2007; 18: 25-32.

[19]Matzler, K., Pichler, E.A. and Hemetsberger, A. Who is spreading the word? The positive influence of extraversion on consumer passion and brand evangelism. Marketing Theory and Applications, 18, (2007), 25-32.

[20] Shimp, T.A. and Madden, T.J. Consumer-object relations: A conceptual framework based analogously on Sternberg's triangular theory of love. Advances in Consumer Research, 15, 1 (1988), 163-168.

[21]Fournier, S. Consumers and their brands: Developing relationship theory inconsumer research. Journal of Consumer Research, 24, 4 (1998), 343-353.

[22] Swimberghe, K.R., Astakhova, M. and Wooldridge, B.R.A new dualistic approach to brand passion: Harmonious and obsessive. Journal of Business Research, 67, 12 (2014), 2657-2665.

[23] Albert, N., Merunka, D. and Valette-Florence, P. Brand passion: Antecedents and consequences. Journal of Business Research, 66, 7 (2013), 904-909.

[24] Cardon, M.S. Is passion contagious? The transference of entrepreneurial passion to employees. Human Resource Management Review, 18, 2 (2008), 77-86.

[25]Li, W. and Ke, Y.Social Commerce: The Critical Role of Argument Strength and Source Dynamism of eWOM. In PACIS, The 18th Pacific Asia Conference on Information Systems, June 24-28 (2014), Chengdu, China.

[26] Pourazad, N. and Pare, V. Conceptualising the Behavioral Effects of Brand Passion among Fast Fashion Young Customers. In Proceedings of the Sydney International Business Research Conference, University of Western Sydney Campbelltown, Australia, April 17-19, (2015).

[27] Dholakia, U.M., Bagozzi, R.P. and Pearo, L.K.A social influence model of consumer participation in network-and small-group-based virtual communities. International Journal of Research in Marketing, 21, 3 (2004), 241-263.

[28] Gefen, D. and Straub, D.W. The relative importance of perceived ease of use in IS adoption: a study of e-commerce adoption. Journal of the Association for Information Systems, 1, 1 (2000), 1-28.

[29] Hassanein, K. and Head, M. Manipulating perceived social presence through the web interface and its impact on attitude towards online shopping. International Journal of Human-Computer Studies, 65, 8 (2007), 689-708. 
[30] Cui, N., Wang, T. and Xu, S. The influence of the social presence on consumers' perceptions of the interactivity of web sites. Journal of Interactive Advertising, 11, 1 (2010), 36-49.

[31] Kumar, N. and Benbasat, I. Research note: the influence of recommendations and consumer reviews on evaluations of websites. Information Systems Research, 17, 4 (2006), 425-439.

[32] Sawhney, M., Verona, G. and Prandelli, E. Collaborating to create: The Internet as a platform for customer engagement in product innovation. Journal of Interactive Marketing, 19, 4 (2005), 4-17.

[33] Wu, G. The mediating role of perceived interactivity in the effect of actual interactivity on attitude toward the website. Journal of Interactive Advertising, 5, 2 (2005), 29-39.

[34] Mollen, A. and Wilson, H. Engagement, telepresence and interactivity in online consumer experience: Reconciling scholastic and managerial perspectives. Journal of Business Research, 63, 9 (2010), 919-925.

[35] Cardon, M.S., Gregoire, D.A., Stevens, C.E. and Patel, P.C.Measuring entrepreneurial passion: Conceptual foundations and scale validation. Journal of Business Venturing, 28, 2 (2013), 373-396.

[36] Cardon, M.S. and Kirk, C.P. Entrepreneurial Passion as Mediator of the Self-Efficacy to Persistence Relationship. Entrepreneurship Theory and Practice, 39, 5 (2015), 1027-1050.

[37] Case, J. Alienation and engagement: Exploring students' experiences of studying engineering. Teaching in Higher Education, 12, 1 (2007), 119-133.

[38] ONTSI. Informe Anual La Sociedad en Red 2013, Observatorio Nacional de las Telecomunicaciones y de la Sociedadde la Available http://www.ontsi.red.es/ontsi/sites/default/files/informe_anual_la_sociedad_en_red_2013_ed._2014.pdf. Accessed February / 10, 2015.

[39] Gefen, D. and Straub, D.W. Managing user trust in B2C e-services. E-service Journal, 2, 2 (2003), 7-24.

[40] Shen, J. Social comparison, social presence, and enjoyment in the acceptance of social shopping websites. Journal of Electronic Commerce Research, 13, 3 (2012), 198-212.

[41] Song, J.H. and Zinkhan, G.M.Determinants of perceived web site interactivity. Journal of Marketing, 72, 2 (2008), 99-113.

[42] McMillan, S.J. and Hwang, J.Measures of perceived interactivity: An exploration of the role of direction of communication, user control, and time in shaping perceptions of interactivity. Journal of Advertising, 31, 3 (2002), 29-42.

[43] Liu, Y. Developing a scale to measure the interactivity of websites. Journal of Advertising Research, 43, 2 (2003), $207-216$.

[44] Koufaris, M. Applying the technology acceptance model and flow theory to online consumer behavior. Information Systems Research, 13, (2002), 205-223.

[45] Kim, Y.J. and Han, J. Why smartphone advertising attracts customers: A model of Web advertising, flow, and personalization. Computers in Human Behavior, 33, (2014), 256-269.

[46] Baldus, B.J., Voorhees, C. and Calantone, R. Online brand community engagement: Scale development and validation. Journal of Business Research, 68, 5 (2015), 978-985.

[47] Liang, T., Ho, Y., Li, Y. and Turban, E. What drives social commerce: The role of social support and relationship quality. International Journal of Electronic Commerce, 16, 2 (2011), 69-90.

[48] Nunally, J.C. Psychometric theory. 2nd ed. New York: New York: McGraw-Hill; 1978.

[49] Nurosis, M.J. SPSS. Statistical data analysis. Spss Inc 1993.

[50] Hair, J., Anderson, R., Tatham, R. and Black, W. Multivariate Data Analysis. New Jersey: Prentivce-Hall International. 1999.

[51] Kaiser, H.F. A second generation little jiffy. Psychometrika35, 4 (1970), 401-415.

[52] Kaiser, H.F. Little Jiffy, Mark IV. Educational and Psychological Measurement, 34, (1974), 111-117.

[53] Jöreskog, K.G. Statistical analysis of sets of congenic tests. Psychometrika, 36, 2 (1971), 109-133.

[54]Fornell, C. and Larcker, D.F. Structural equation models with unobservable variables and measurement error: Algebra and statistics. Journal of Marketing Research, 18, (1981), 39-50.

[55] Hildebrandt, L. Attitudes and values as predictors of energy information behavior patterns. Advances in Consumer Research, 11, 1 (1984), 574-578.

[56] Kline, R.B. Principles and Practice of Structural Equation Modeling. 3rd ed. New York: Guilford Press; 2011.

[57] Kim, S. Web-interactivity dimensions and shopping experiential value. Journal of Internet Business, 9, (2011), 1-25. 
Herrando et al / Vol. 3, No. 3, December 2020, pp. 136-145

[58]Kim, S. and Park, H. Effects of various characteristics of social commerce (s-commerce) on consumers' trust and trust performance, International Journal of Information Management, 33, (2013), 318-332.

[59] Hausman, A.V. and Siekpe, J.S. The effect of web interface features on consumer online purchase intentions, Journal of Business Research, 62, (2009), 5-13. 